\title{
High Strain Rate Mechanics of Polymers: A Review
}

\author{
Clive R. Siviour ${ }^{1} \cdot$ Jennifer L. Jordan $^{2}$ (D)
}

Received: 6 November 2015/ Accepted: 19 January 2016/Published online: 25 January 2016

(C) Springer Science+Business Media New York (outside the US) 2016

\begin{abstract}
The mechanical properties of polymers are becoming increasingly important as they are used in structural applications, both on their own and as matrix materials for composites. It has long been known that these mechanical properties are dependent on strain rate, temperature, and pressure. In this paper, the methods for dynamic loading of polymers will be briefly reviewed. The high strain rate mechanical properties of several classes of polymers, i.e. glassy and rubbery amorphous polymers and semi-crystalline polymers will be reviewed. Additionally, time-temperature superposition for rate dependent large strain properties and pressure dependence in polymers will be discussed. Constitutive modeling and shock properties of polymers will not be discussed in this review.
\end{abstract}

Keywords Polymer $\cdot$ High strain rate $\cdot$ Split Hopkinson pressure bar - Taylor test

\section{Introduction}

An understanding of the mechanical properties of polymers over a range of strain rates, temperatures, and pressures is required in fields such as military applications, automotive, aerospace, and medical devices. As well as being governed by the composition and microstructure of the materials, these properties are highly dependent on a number of

Jennifer L. Jordan

jennifer.jordan.6@us.af.mil

1 Department of Engineering Science, University of Oxford, Oxford OX13PJ, UK

2 Air Force Office of Scientific Research, Arlington, VA 22203, USA external factors such as pressure, temperature, and frequency (strain rate).

Some of the first papers on dynamic loading studied the material response of polymers including Kolsky's 1949 paper [1] and Davies and Hunter [2]. Over the past 40 years, the mechanical response (principally the relationship between stress and strain) of a number of polymers has been characterized at strain rates between $10^{-4}$ and $10^{5} \mathrm{~s}^{-1}$, see for example [3-5]. Most polymers exhibit time dependent mechanical behavior, as evidenced by rate dependent elastic moduli, yield strength, and post-yield behavior. Over a range of temperatures and strain rates, the mechanical response of a polymer may change from rubbery to ductile plastic to brittle [6-12]. Additionally, many rubbery polymers can exhibit large, recoverable deformation, and, for hyperelastic materials, experimental measurements at large strain may be required to characterize the strain hardening [13].

Time-temperature superposition has been used to address the response of polymers over a range of strain rates by comparing the temperature and strain rate dependencies of yield stress. This is an extension of the wellknown time-temperature superposition that is often applied to modulus data [14]. Although, the time-temperature superposition of yield stress was initially studied in the 1970s [15-18], it was not applied again in this context until research by Siviour et al. ([19], in which a linear mapping between strain rate and temperature was used to show that rate dependence in many glassy amorphous polymers was affected by lower order $\beta$ transitions, which causes increased strength and stiffness. Alternatively, the increased strength in rubbery amorphous polymers is accounted for by the change in molecular mobility during the glass transition, or $\alpha$-transition. The key feature is that a transition, which is typically observed below room temperature, is observed at room temperature for high strain 
rates, as the transition temperature increases with increasing strain rate $[5,15,16,19,20]$

The effect of confining pressure has not been well studied in polymers, and there are limited reports in the literature [21, 22]. Quasi-static experiments have shown that increased hydrostatic confining pressure results in linearly-dependent, increased yield strength and decreased strain to failure in tension [22]. This pressure dependence manifests itself in differences between the tensile and compressive yield stresses, which can aid in the determination of pressure dependence without a requirement for the complex loading apparatus required for applying hydrostatic pressure [18, 20,23].

Constitutive models of polymers typically depend on the structure of the polymer (amorphous or semi-crystalline) as well as whether the polymer is glassy over the temperature range of interest. The parameters for these constitutive models typically require a considerable amount of experimental data to determine the model parameters. Although these models require significant effort to parameterize and, once parameterized, are specific to the particular material that was characterized, they are very useful for utilizing polymers in engineering simulations, such as ABAQUS.

The first model to describe the rate dependent yield in glassy polymers was proposed by [24]. This theory allows for multiple rate activated processes, which are related to specific degrees of freedom of the polymer chains, to control the yield [20]. The molecular motions of the polymer chains become restricted at particular temperatures/strain rates, the effects are seen in increased yield strength.

The first 1D model to describe polymer behavior based on the Ree and Eyring [24] theory was proposed by Haward and Thackray [25]. This model employed a Hookean spring and Eyring dashpot to capture the intramolecular resistance to chain segment rotation, and the Langevin spring represents the entropic resistance to chain alignment. The nonlinear dashpot(s) are responsible for the rate-dependent yield in the material [26]. Multiple dashpots may be used to model multiple molecular processes that affect yield, e.g. $\alpha$ - and $\beta$-transitions. The Langevin spring accounts for the strain hardening post-yield due to the alignment of the macromolecular network built of entangled polymer molecules [26]. A large family of 3D pressure, temperature, and strain rate dependent models [2729] has developed based on the Ree-Eyring [24] theory. The most recent of these model developments by Mulliken and Boyce [20] provides a three-dimensional temperature, pressure, and rate dependent finite-strain model capable of capturing both the $\alpha$ - and $\beta$-transitions. These empirical models describe the behavior of glassy polymers well. However, since they are empirical, they require a large data set to adequately calibrate all of the model parameters, which can make them unwieldy for describing many materials. Another model which directly links the constitutive behavior of polymers to the frequency and temperature dependence, thereby implicitly including the effects of lower order transitions on the rate dependence is the Porter-Gould model [30-34]. This model also has the advantage of being able to predict a number of key polymer properties from knowledge of the polymer chain composition without the need for extensive calibration data.

This review includes a brief discussion of experimental techniques to characterize the mechanical response of polymers. For additional detail, on relevant experimental techniques, the reader is referred to the paper by Chen [35] in this issue. The primary focus of this paper is the properties of different classes of polymers, as well as properties of polymers across classes, i.e. time-temperature superposition and pressure dependence. Constitutive modeling and shock properties of polymers is beyond the scope of this review.

\section{Experimental Techniques for Polymers}

Over the past 100 years, a wide range of experimental apparatus has been developed for characterizing the response of materials to deformation at different strain rates, as seen in Fig. 1. Many of these techniques have been specially adapted for polymer characterization. The change between experimental techniques to capture different rates can cause doubts as to whether the observed responses are really an intrinsic material behavior or an artifact of the experimental testing technique, and it is challenging,

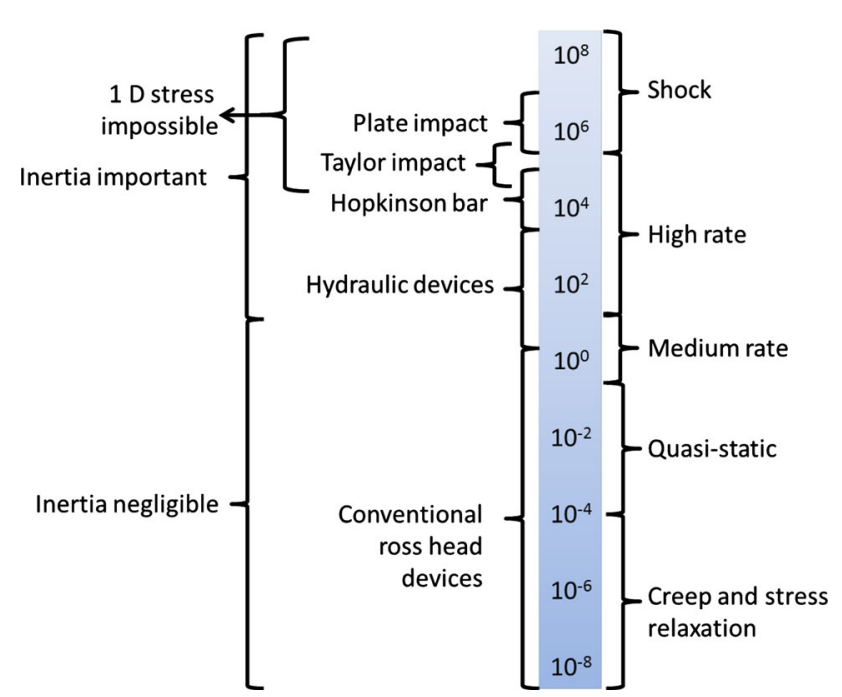

Fig. 1 Approximate division of strain rate regimes (in $\mathrm{s}^{-1}$ ) and the experiments used to investigate these regimes. Further information on the various techniques can be found in Field et al. [36] 
experimentally, to overlap the range of rates at which the techniques work. A brief overview of experimental techniques relevant to polymer characterization is presented in this section. For a more detailed review of high rate experimental techniques for low impedance materials, the reader is referred to the paper by Chen [35] in this issue, and for a general overview of experimental methods, the reader is referred to Field et al. [36].

\section{Quasi-static Experiments}

For quasi-static experiments, conventional servo-hydraulic and screw-driven machines are typically used. Such testing machines have been available commercially since the late nineteenth Century $[37,38]$ and have gone through several evolutions, moving from purely mechanical machines to sophisticated electromechanical and servo-hydraulic systems with advanced electronic control.

Dynamic Mechanical Analysis (DMA) machines apply oscillating displacements with systematic variations of temperature and/or frequency (up to approximately $100 \mathrm{~Hz}$ ). By measuring force and displacement as functions of time, with particular reference to the phase of these quantities, it is possible to calculate the complex modulus and loss tangent of a polymeric material. Commonly used configurations include single and dual cantilever, tension, and compression. DMA results provide valuable insight into the temperature and frequency dependence of features such as the $\alpha$ - and $\beta$-transitions in the material. For comparison to other mechanical properties, the frequencies from DMA experiments can be converted to strain rates using the following approximation, which is commonly found in the literature [20]:

$\dot{\varepsilon} \approx \frac{\Delta \varepsilon}{\Delta t}=\frac{\varepsilon_{0}}{1 / 4 f}=4 f \varepsilon_{0}$

where $\varepsilon_{0}$ is the strain amplitude reported by the DMA, and $f$ is the oscillation frequency. It should be noted, however, that these strain rates are approximations, giving the mean rate seen in a tension or compression specimen. For bending or cantilever arrangements the strain rates in the specimen vary considerably through the specimen volume. However, as will be described later, many researchers have had success relating DMA measurements to those obtained in other testing apparatus.

\section{Intermediate Strain Rates}

Intermediate strain rate experiments (between circa 1 and $500 \mathrm{~s}^{-1}$ ) pose a significant challenge for all material characterization programs. The frequency at which experimental data are required is similar to the natural frequency of both the loading apparatus (e.g. piston) and the instrumentation (e.g. load cell). In addition, it is necessary to overcome the effects of the inertia of the apparatus, so that high speed deformations can be applied after a very short period of acceleration. Hydraulic machines are often used; however, systems based on dropping weights [39-48], fly wheel systems [49, 50], expanding ring [51], cam plastometer [52], very long Hopkinson bars [53], or the 'wedge bar' [54] have also been applied successfully. Accurate experiments in this strain rate regime are key because molecular mobility transitions often become activated between 1 and $1000 \mathrm{~s}^{-1}$.

\section{Dynamic Loading: Split Hopkinson Pressure Bar}

Although a number of techniques have been developed to measure material properties at high strain rates, the splitHopkinson pressure bar [55-58], or Kolsky bar, has now become ubiquitous for materials characterization between 500 and $10^{4} \mathrm{~s}^{-1}$, or even higher if miniaturized systems are used [59,60]. A schematic of the split Hopkinson pressure bar system at the Air Force Research Laboratory, Eglin AFB, FL is shown in Fig. 2a. The data acquisition systems tend to be specific to the SHPB laboratory. However, the bar system itself has common elements across all laboratories.

During an SHPB test, the specimen is sandwiched between two slender rods, known as the input and output bars, or incident and transmitted bars, which are instrumented with strain gauges, or, more recently photon Doppler velocimetry (PDV) [61]. A loading system, typically a gas gun, is used to propel a shorter third rod, or striker, into the incident bar. This generates a stress wave, shown as the incident signal in Fig. 2a, which propagates down the bar to the specimen. At the bar-specimen interface, the change in impedance (density times sound speed) between the bar and the specimen causes some of the wave to be reflected back down the input bar and some to be transmitted to the output bar, forming the reflected and transmitted signals in Fig. 2a, respectively. Typically, all three waves are measured using strain gauges mounted on the incident and transmitted bars; although quartz gauges [62-64] and interferometric techniques [59, 65] have been used. Representative voltage-time curves are shown in Fig. $2 b$, where the compressive pulse is shown as positive. It is common practice to mount two strain gauges at each location which are diametrically opposed to each other, which will result in cancelling out bending waves and, subsequently, measurement of a purely compressive pulse. Using the three waves, and a simple 1D wave analysis, the velocities and forces at the two bar specimen interfaces, Fig. 3a, can be calculated from the following equations: 

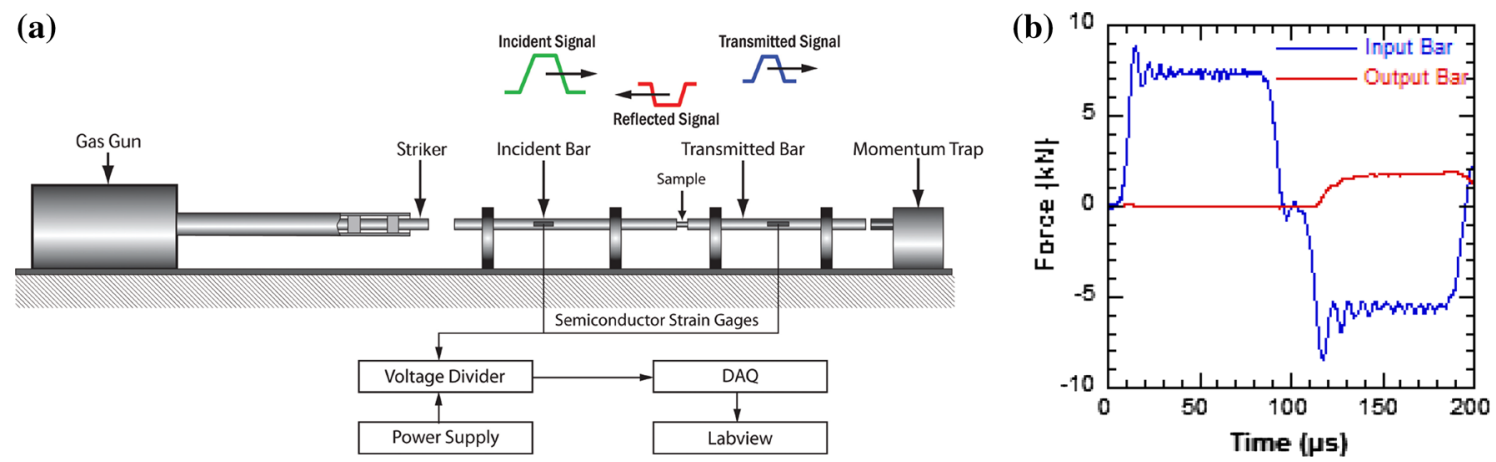

Fig. 2 a Schematic of Split Hopkinson Pressure Bar at the Air Force Research Laboratory, Eglin AFB, FL and b representative voltage-time curves for an SHPB experiment

Fig. 3 a Forces and displacements at the barspecimen interfaces in a split Hopkinson pressure bar and b comparison of forces calculated from one-wave and two-wave analyses

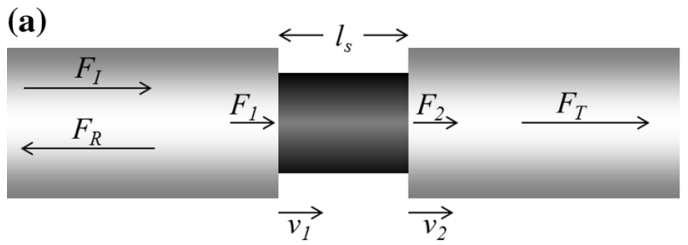

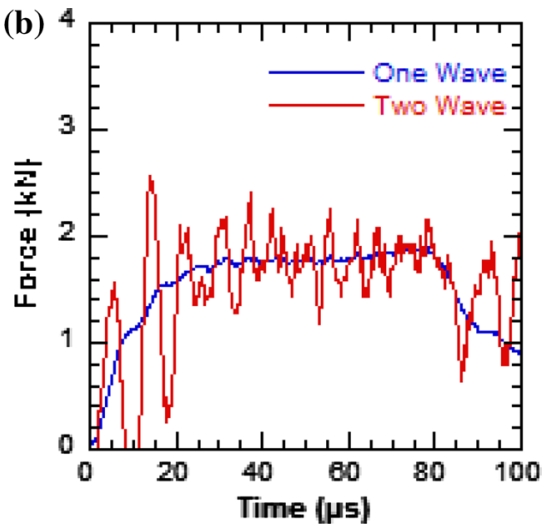

$F_{1}=F_{I}+F_{R}$

$F_{2}=F_{T}$

$v_{1}=\frac{F_{I}-F_{R}}{\rho c A_{b}}$

$v_{2}=\frac{F_{T}}{\rho c A_{b}}$

where $F_{I}, F_{R}$, and $F_{T}$ are the forces associated with the incident, reflected, and transmitted waves, $\rho$ is the density of the bar, $A_{b}$ is the area of the bars, and $\mathrm{c}$ is the wavespeed of the bars defined as:

$c=\sqrt{\frac{E}{\rho}}$

where $E$ is the Young's modulus of the bar. Typically, the same material is used for both of the bars, but it is simple to modify Eqs. (5) and (6) if different bar materials are used.

It is usual to assume that the specimen is in stress equilibrium during deformation, which occurs after a number of wave oscillations in the specimen, as shown in Fig. 3(b). If this is the case, then the force supported by the specimen is equal to both $F_{1}$ and $F_{2}$ and the stress-strain relationship in the specimen can be calculated using the forces and bar velocities. It is necessary to ensure that polymeric, or other low wave speed specimens, are in equilibrium [66]. This is typically done by comparing the two forces. For polymeric materials, considerable strains can develop before equilibrium is achieved as the stress wave oscillates in the specimen $[67,68]$, and specimens should be designed to allow this to happen before material properties are measured from stress-strain curves.

The one wave stress can be calculated from the forces by:

$\sigma(t)=\frac{F_{T}(t)}{A_{s}(t)}$

where $A_{s}$ is the area of the specimen. The engineering stress can be calculated using the constant initial area, and the true stress can be calculated using the area as a function of time. The two wave stress can be calculated from the forces by:

$\sigma(t)=\frac{F_{I}(t)+F_{R}(t)}{A_{s}(t)}$

The specimen equilibrium can be verified by comparing the one wave and two wave stresses. When the specimen is in equilibrium, the two wave stress will oscillate around the one wave stress. 
The strain rate in the sample can be determined using all three forces:

$\dot{\varepsilon}(t)=\frac{F_{I}(t)-F_{R}(t)-F_{T}(R)}{\rho c A_{b}}$

which can be numerically integrated to determine the strain as function of time.

The propagation of the stress wave in the bar can be dispersive when the wavelength is on the same order of magnitude as the bar diameter $[69,70]$. Dispersion of the wave will result in an increased rise time and oscillations about the peak stress, as seen in Fig. 1. There are methods for correcting for the dispersion, one of which has been presented by Gorham [71]. In these methods, the incident and transmitted signals are translated to frequency space using a Fast Fourier Transform (FFT). The signals are then corrected by changing the phase of each component by a given amount that is a function of frequency. The corrected signals are then converted back to real space using an inverse FFT (Fig. 4).

The low impedance of polymeric samples, which can result in a very small transmitted signal, presents additional considerations during testing. There are several approaches to mitigating the effect of the low impedance: increased sensitivity or additional gauges, changing the cross-sectional area of the bars or specimens, pulse-shaping and changing the pressure bar material [72]. Johnson et al. [72] carried out an experimental comparison with polyurea of these different techniques and found that they all had their own advantages and disadvantages, which must be considered when designing a particular characterization experiment. An extensive review of testing techniques for soft materials, e.g. elastomers, biological tissues, and foams, can be found in Chen and Song [73].

In traditional SHPB systems, foil strain gauges, which have a gauge factor $\sim 2$, are mounted on the surface of the

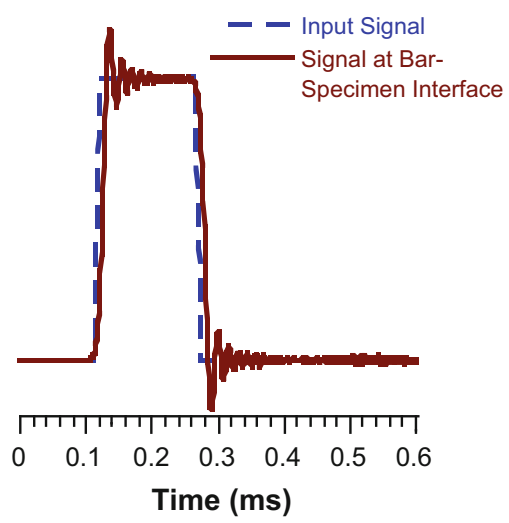

Fig. 4 Dispersion of a stress pulse produced by traveling $1.5 \mathrm{~m}$ in a $25.4 \mathrm{~mm}$ diameter steel bar. Signal at bar-specimen interface has been shifted in time to overlay the input signal for comparison incident and transmitted bars. For polymeric materials, these foil gauges can result in transmitted signals that cannot be distinguished from the noise. Increased sensitivity semiconductor strain gauges, which have a gauge factor $\sim 140$ can be used to enable accurate measurement of small transmitted signals [74]. Additionally, piezoelectric gauges, such as $\mathrm{x}$-cut quartz or lead zirconium titanate (PZT), can be placed in the experiment to provide enhanced sensitivity or to directly measure input and output forces [62-64, 75]. Early experiments with quartz gauges placed them directly in contact with the specimen [63]. However, polymeric materials, with large diameter increases during testing, will damage the quartz gauges. Chen et al. [62] embedded an x-cut quartz gauge in a hollow aluminum transmitter bar, since the quartz gauge is more sensitive than the surface mounted strain gauges. They found that the stress measurements using this modified system were three times more sensitive than a traditional steel bar. Kendall et al. [64] utilized PZT crystals mounted on either side of the specimen near the ends of the incident and transmitted bars and were able to measure loads of less than $10 \mathrm{~N}$ on a soft, rubbery polymer.

A second approach to addressing the low impedance of polymers is to change the cross-sectional area of the specimen or the bars. Increasing the cross-sectional area of the specimens to obtain a larger signal poses difficulties since it would require larger bars, which may be prohibited by the available laboratory facilities. Chen et al. [76] pioneered the use of hollow, aluminum transmitted bars. Using aluminum reduces the impedance of the bar material itself, and the hollow bar provides a reduced cross-sectional area. Both of these modifications resulted in increased transmitted signal, and the ability to reduce the data.

A third approach, is to change the bar material to either a low impedance metal, e.g. titanium, magnesium alloy or aluminum, or a polymer, e.g. polymethylmethacrylate (PMMA), PC, or nylon [77-88]. Low impedance metallic bars do not require any changes to the experimental apparatus or data reduction. Use of viscoelastic, polymeric bars requires more complex data reduction correcting for dispersion and attenuation occurring in the bar. The polymers used for the bars must be well characterized at high rates in order to determine the specimen properties from the signals measured on the bars [79].

Specimens for SHPB experiments are typically right circular cylinders. When designing specimens for high rate experiments, two key factors must be taken into account:

(1) The specimens must be short enough to allow stress equilibrium to occur in a reasonable time scale [89]. A reasonable rule of thumb is that three wave reverberations are required along the specimen 
length. For glassy polymers, this limits the specimen length to about $5 \mathrm{~mm}$, and less for rubbery polymers.

(2) Specimen inertia must be considered [71, 90]. When a specimen is loaded, some force is required to overcome the intrinsic material strength, while some is required to accelerate the material to the high deformation speeds, in both the axial and radial directions. Gorham [91] calculated that the pressure measured on the output bar is given by

$P_{2}=\sigma_{y}-\rho\left(\frac{r^{2}}{8}-\frac{h^{2}}{6}\right) \ddot{\varepsilon}+\rho\left(\frac{r^{2}}{16}-\frac{h^{2}}{6}\right) \dot{\varepsilon}^{2}-\frac{\rho h \dot{v}}{2}$

where $\sigma_{y}$ is the intrinsic material strength, $r$ and $h$ are the specimen radius and height, respectively, and $\dot{v}$ is the velocity of the output bar. This equation, which has been derived for an incompressible specimen, can be used as a guide to specimen design, ensuring that the inertial contribution is significantly smaller than the actual material strength.

Once the experimental configuration has been determined, control of the incident pulse can aid in ensuring that specimen deformation is occurring at a constant rate [73]. The incident pulse can be controlled through the use of pulse shapers, which are thin layers of metals or plastic placed on the impact surface of the incident bar. The pulse shaper should be chosen to ensure that the reflected signal has a plateau, which will ensure constant strain-rate deformation in the specimen [73]. Additionally, pulse shapers will reduce the oscillations due to wave dispersion in the bar.

Lubrication is an important consideration in all compression experiments, but especially in high rate testing of polymers, where low sound speeds mean that short specimens are required, and the low strengths often encourage the use of specimens with large diameters. Hence, the aspect ratio of the specimen $(h / r)$ is small, which can lead to significant frictional effects. If there is excessive friction, a barreling effect is observed, causing stress inhomogeneity and an increase in the measured specimen strength: such tests are not valid for the measurement of bulk properties of a material. Studies of different lubricants $[47,92,93]$ have shown that paraffin wax, petroleum jelly, and molybdenum disulfide grease provide adequate lubrication for high strain rate experiments.

The change from broadly isothermal to broadly adiabatic conditions as the strain rate increases is an important feature of high rate deformation, and the associate temperature rise as mechanical work is converted to heat during plastic deformation must be considered alongside the dependence on initial temperature when considering material response. Although the strain rate at which an experiment may be considered adiabatic depends on both material properties and specimen size, for typical tests on polymers it may be of the order 0.01-1 $\mathrm{s}^{-1}$ [94]. Important studies involving the temperature rise in specimens during high rate deformation have been conducted by a number of authors [95-101]. A notable achievement was by Chou et al. [95], who showed that the temperature rise in specimens increases significantly after yield. Furthermore, Arruda et al. [96] presented visible increases in strain softening with increases in strain rate, coupled with corresponding temperature measurements using infrared techniques. Additionally, Garg et al. [97] used infrared techniques to measure the temperature rise of PC undergoing high rate deformation. Good agreement was observed between the experimentally measured temperature rise and the "theoretical" rise obtained by assuming that $100 \%$ of the mechanical work is converted to heat and adiabatic conditions prevail. Hillmansen et al. [98, 99] studied plastic work being converted to heat by studying high density polyethylene (HDPE) and found, similarly, that the plastic work at large strains was approximately $100 \%$ converted to heat.

\section{Dynamic Loading: Taylor Tests and Dynamic Tensile Extrusion}

The above testing methods are primarily used to characterize materials and develop parameters for constitutive models. Taylor testing and Dynamic Tensile Extrusion are primarily used to validate models as they involve complex loading of the material. Taylor testing was developed in 1946 [102-105], primarily to measure the dynamic yield strength of metals. However, event these early tests were used to investigate the underlying deformation mechanism through microstructure [105]. In the original test, a slender rod of material is impacted at high speed into a rigid, semiinfinite anvil. The specimen is recovered, and the dynamic yield strength is assessed using the initial and final lengths and the length of the plastic deformation zone [103]. However, this purely post-mortem analysis is not sufficient for polymers, due to the viscoelastic recovery of the materials. With the advent of high speed cameras, the ability to measure the polymer deformation in situ became possible. Additionally, experimental studies and theoretical analysis by Hutchings [106, 107] brought together a new analysis appropriate for these materials. The complex loading in compression of the Taylor test, where stress, strain rate, and final strain vary within the specimen makes it an ideal test for validating constitutive models, where the complex loading is thought to provide a more robust test of the model [36]. In polymers, the test has been used to understand the behavior of the materials under complex loading for modeling efforts [108-113] and to elucidate phase transitions in the polymeric materials $[12,114]$. 
More recently, Dynamic-Tensile-Extrusion (Dyn-TenExt) has been developed to provide model validation in dynamic tension $[115,116]$. In this test, a sphere of material is fired through a conical extrusion die. Initially, the sphere is not affected by the die; however, the trailing side decelerates creating a ligament between the two portions of the sphere, which is pulled in high rate tension to high strains and, ultimately, failure. High speed photography is used to capture the deformation and compare with results from computer models. Several polymers have been studied showing that both the deformation and failure behavior can be directly observed and the internal history can be understood through integration with finite element simulations [117-122].

\section{Dynamic Response of Polymers}

The dynamic response of polymers dates to the first paper using a split bar configuration for high rate testing [1], and interest in the dynamic response of these materials has continued to the present. Walley and Field [5] published an extensive set of data characterizing the compressive stressstrain response over a range of strain rates for a broad range of polymers. They observed a range of material responses depending on the polymer structure. In this section, the dependence of mechanical response on the polymer structure will be discussed for different classes of polymers, namely glassy amorphous polymers and semi-crystalline polymers.

\section{Glassy Amorphous Polymers}

There are several glassy polymers that have been extensively studied at high strain rate in the literature, including polymethylmethacrylate (PMMA) [16, 95, 100, 123-132], polycarbonate (PC) $[15,18-20,100,110,124,126,127$, 133-136], polyvinylchloride (PVC) [137, 138] and varying classes of epoxy [23, 74, 139-141]. The large number of studies on a "single" material indicates that it is critical to understand the pedigree of the polymer being tested, including processing history and storage.

Representative compressive stress-strain curves for these materials across a range of strain rates are shown in Fig. 5, which show many similarities across the class of materials. Typically, the stress-strain curve has an initial viscoelastic behavior which becomes increasingly nonlinear as strain increases until it reaches a peak stress. The peak stress is followed by strain softening and then strain hardening. Hasan and Boyce [131] describe the stressstrain response in terms of the evolution of shear transformation sites, where the initial material has a number of sites with a probability of transformation within the timeframe of the experiment. As stress is applied to the material (viscoelastic rise), transformation sites with high local free volume and, subsequently, low activation energy begin to yield and flow, and the corresponding transformation strain energy is stored in the non-transformed "matrix," which creates a back stress that initially inhibits further transformation. With increasing stress, transformation sites with higher activation energy can be accessed resulting in increasingly non-linear stress-strain response. The surrounding material stores the transformation strain energy, which exerts a back stress on the transformed material. As the applied stress increases, transformation sites with higher activation energy are accessed and the surrounding material can no longer absorb the transformation strain energy, which results in the creation of new defects, i.e. sites with high local free volume. These new sites result in strain softening in the material, where there are sites available to transform with lower activation energy. At this point, the material is in a steady-state condition where the mobile regions are prolific through the material allowing for indefinite plastic flow [131]. At higher strains, resistance to polymer chain alignment causes strain hardening in the material [96]. However, with increasing strain rate, this strain hardening effect is balanced by adiabatic heating in the material, which ultimately dominates over the hardening from resistance to polymer chain alignment [94, 96, 124, 130, 137, 142]. Finally, in the case of PMMA (Fig. 5a), at high strain rates the material fails catastrophically due to the inability to access particular molecular side chain motions at these fast rates.

The strain rate dependence of these polymers becomes more obvious when the peak stress is plotted versus log strain rate as shown in Fig. 6 for the same range of semicrystalline polymers presented in Fig. 5. The most interesting observation in these materials is the increased strain rate sensitivity at higher strain rates, which has been observed in a wide variety of polymer materials, in addition to those presented. However, caution should be taken when interpreting these results for three reasons. A similar increase in strain rate sensitivity has been observed in metals, e.g. copper [143-145]. Secondly, the strain rates where the increased sensitivity occurs are also those where inertial effects become relevant, i.e. if the specimen is too large, the stress induced by specimen inertia can become significant compared to the polymer strength [146]. Finally, the transition in behavior occurs over the same regime where test equipment changes from screw-driven or hydraulic load frames to split Hopkinson pressure bars.

Careful studies like those conducted on PMMA [128], shown as the blue data points and fitted line in Fig. 6a, and epoxy [74] where experiments are conducted at every decade of strain rate using novel hydraulic loading devices capable of testing the intermediate rate regime reduced the uncertainty associated with the third reason described 
Fig. 5 Representative compressive stress-strain curves for a PMMA [128], b PC [19], c PVC [138], and d epoxy [74] across a range of strain rates

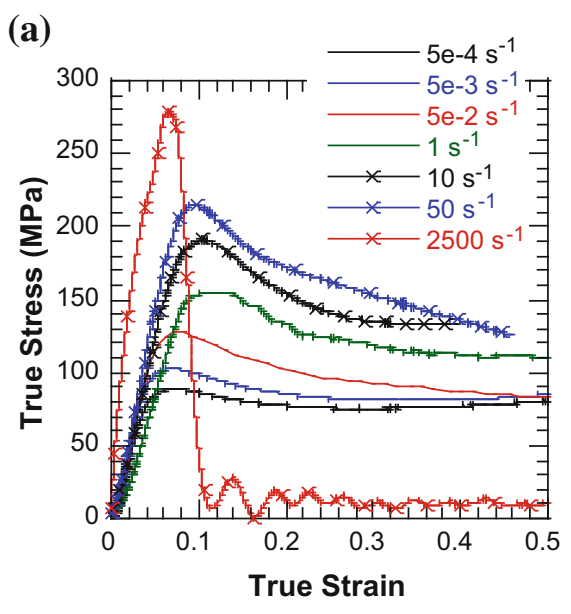

(c)

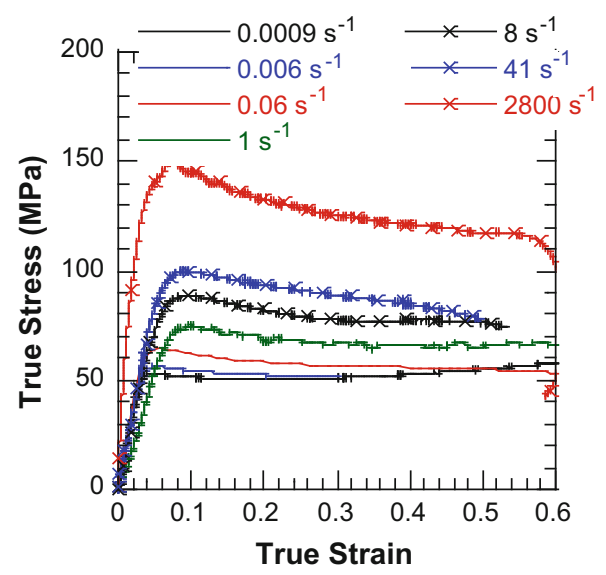

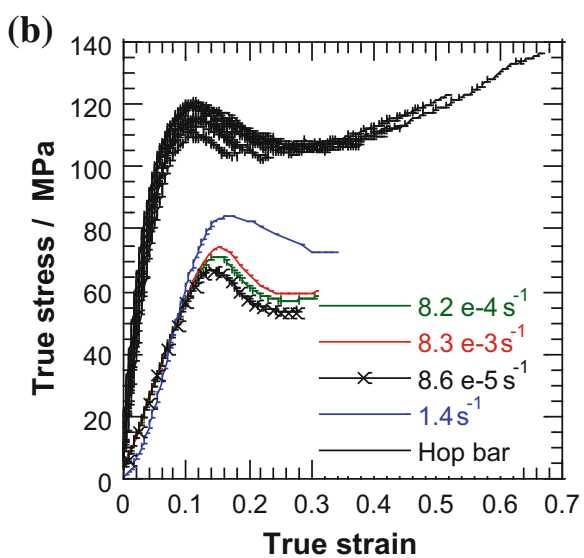

(d)

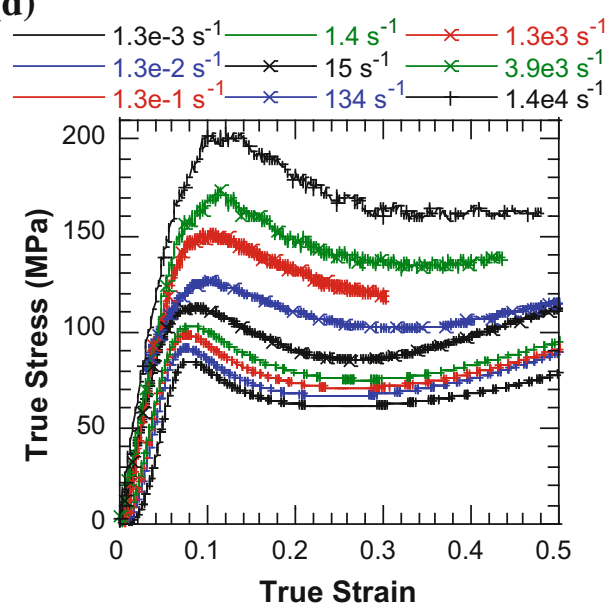

above. Typically, the increase in strain rate sensitivity in glassy polymers is attributed to activation of particular molecular mobility, often due to side chain motion or ring flips called the $\beta$-transition.

There is considerable scatter between the data from different studies, as seen in Fig. 6a, again emphasizing that the polymer pedigree is important in determining the mechanical response. For PMMA, which is used as a reference and window material in shock experiments, understanding the cause of these differences is critical. Consideration of polymer processing, particularly annealing as-received or aged materials, should be done prior to experimentation.

\section{Rubbery Amorphous Polymers}

Characterization of elastomers at high rates of strain presents a number of challenges associated with their relatively low mechanical strength; the most important of these are the low sound speed, which results in the duration of oscillation of stress waves in the specimen being a significant fraction of the duration of the experiment, the increased effect of lateral inertia [90, 147], and the low intrinsic strength leading to poor signal to noise ratios. Furthermore, many elastomers must be deformed to large strains to fully characterize the mechanical response, especially for hyperelastic materials. However, rubbers were some of the first materials to be characterized in split Hopkinson bar experiments [1, 2], and more recently a number of authors have proposed techniques to address these difficulties through modifications to the Hopkinson bar or other similar systems $[57,66]$. These include pulse shaping [62], low impedance Hopkinson bar materials to increase the transmitted force $[76,77,81,82,148]$ or use of more sensitive force gauges to directly measure the force at the specimen bar interface [62-64]. Longer Hopkinson bars may be used to increase the duration of the experiment [53], as can direct impact systems [149], in addition, if stress gauges are combined with optical measurements of specimen deformation, the experiment duration is no longer limited by wave overlapping in the bars and longer durations can be achieved [150]. The challenges associated 
Fig. 6 Peak stress vs. strain rate for a PMMA $[16,95,125$, 128-132], b PC [19], c PVC [138], and $\mathbf{d}$ epoxy [74] across a range of strain rates
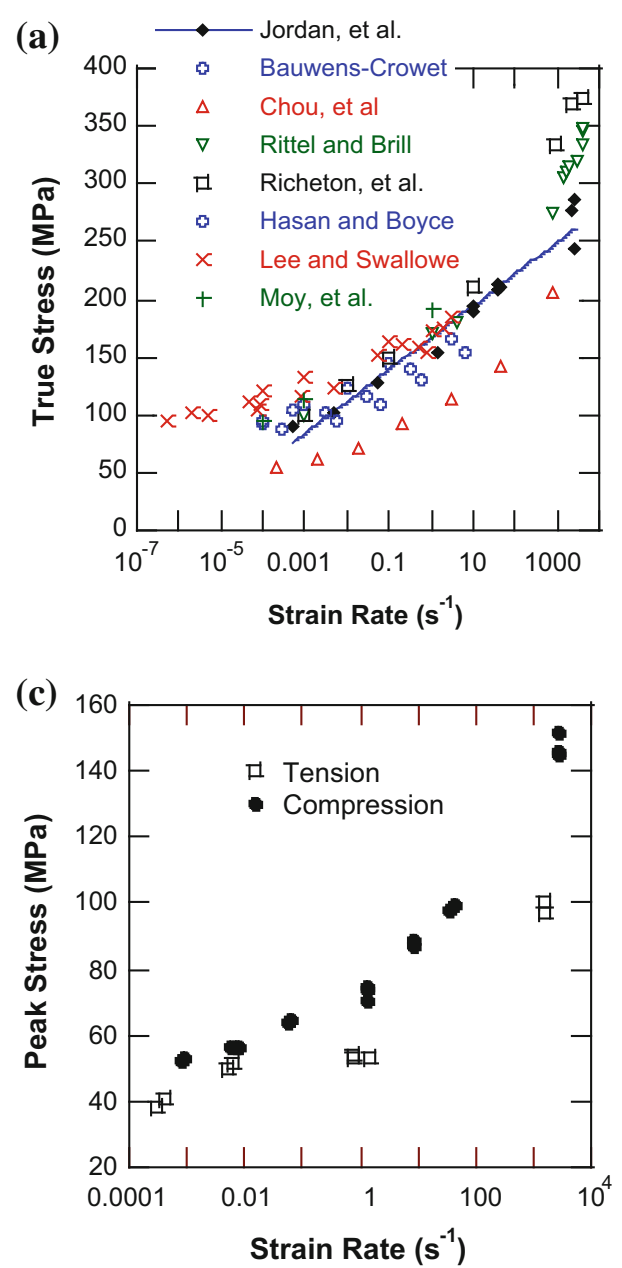
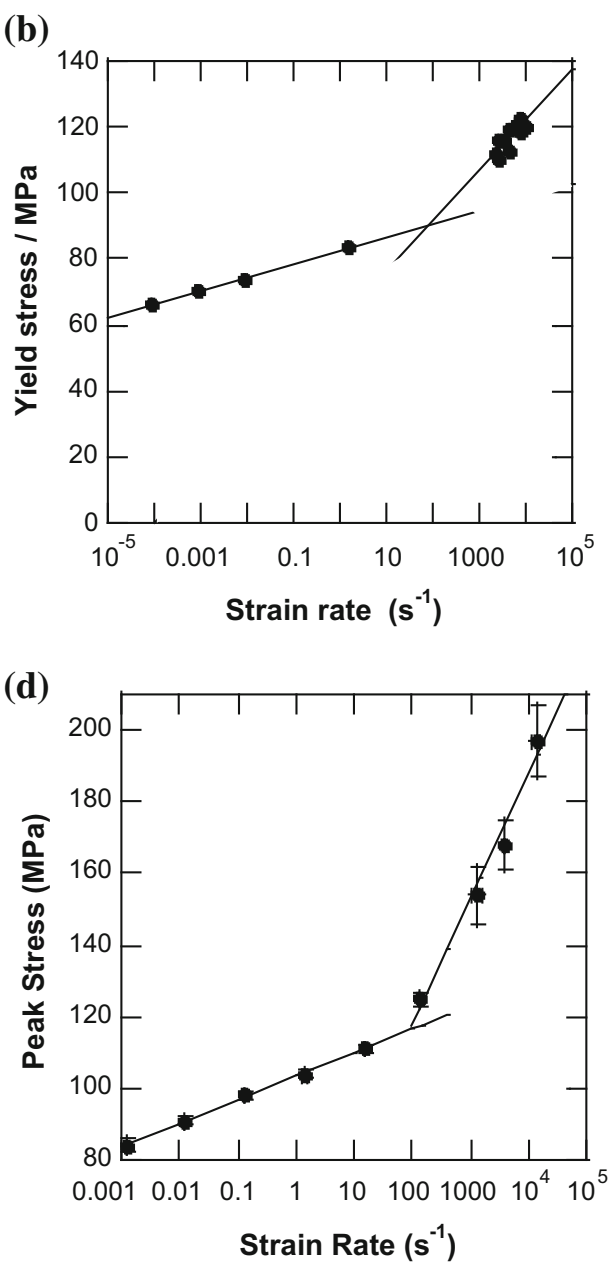

with these elastomers are similar to those experienced when characterizing many biological materials, giving further motivation to the development of suitable experimental techniques.

Materials which have been well-studied in the literature are silicone elastomers [13, 66, 151], plasticized PVC [152, 153] and polyureas [39, 40, 72, 154-159] and polyurethanes [160-162]. The rate dependence of these materials depends strongly on the glass transition, and in particular whether this transition affects the room temperature response at strain rates of interest. At lower rates, or higher temperatures, the response is typically rubbery, may be described by a suitable material model and is a weak function of both rate and temperature; as the rate increases the apparent stiffness of the rubber may increase owing to the viscoelastic nature of the response, or, if the glass transition takes effect, the material may exhibit 'leathery' [155] then glassy behavior.

One of the key limitations of these more established techniques for high rate deformation is that they are not suitable for characterizing material moduli. However, for specimens with low speeds of sound, the wide availability of high speed cameras gives the opportunity to calculate this property from measurements of stress waves propagating in a specimen, either using the wavespeed to infer material properties, or using accelerations as a virtual load cell, combined with direct calculations of strain to calculate the material response [163-169].

\section{Semi-crystalline Polymers}

Semi-crystalline polymers like polypropylene (PP) [4, 5, 92, 95, 170, 171], polytetrafluoroethylene (PTFE) [5, 6, 8 $10,172-177]$, and various classes of polyethylene [108, 136, 178] — low density polyethylene (LDPE), high density polyethylene (HDPE), ultra high molecular weight polyethylene (UHMWPE), and crosslinked polyethylene (PEX) - are widely used in applications that require understanding of the high strain rate response. These materials bring additional complexity over the glassy polymers due to the dependence of properties on the molecular conformation. The percent crystallinity and 
molecular conformation are highly dependent on the processing history.

By far, the most studied polymer in this class of materials is PTFE [5, 6, 8-10, 172-177], which can be thought of as a two-phase structure, with a "rigid" crystalline phase in a matrix of the "softer" amorphous phase. The behavior of PTFE strongly depends on the crystallinity, i.e. increasing the percent crystallinity will increase the strength, similar to particulate composites. PTFE has crystalline phase changes at $19{ }^{\circ} \mathrm{C}$ from Phase II to Phase IV and at $30{ }^{\circ} \mathrm{C}$ from Phase IV to Phase I at ambient pressure [176]. Although Phases II and IV are strongly crystalline, Phase I is sometimes described as mesophase [179]. The crystalline phase has been shown to dramatically effect whether fracture is brittle (Phase II) or ductile (Phases I and IV) [176]. Additionally, the amorphous PTFE has three relaxations, $\gamma$ and $\alpha$, which are similar to glass transitions and $\beta$, which encompasses the crystalline phase transitions between Phases II, IV, and I [6, 180].

PTFE has been shown to have both strain rate and temperature dependence as expected in polymers. An example of the strain rate dependence is shown in Fig. 7a [174] showing a nonlinear viscoelastic region to a distributed yield followed by unrecoverable deformation, viscoplastic flow, and stiffening at large strains [181]. Additionally, the true stress at $15 \%$ strain versus strain rate for a variety of PTFE materials is shown in Fig. 7b. It can be seen that all the materials have a bilinear dependence on strain rate, but there are measureable differences between the individual material types. This is due to the different processing conditions, which result in different fractions of crystallinity, as well as the differing types of PTFE.

Another well studied semi-crystalline polymer is polyethylene, which brings the added complication of varying molecular weights and conformations. Brown et al. [108, 178] have investigated polyethylene with a variety of
conformations-HDPE, UHMWPE, and PEX. They found similarities between UHMWPE and PEX with both showing significant post-yield strain hardening, and HDPE exhibiting higher yield stress and nearly perfectly plastic flow after yield. Interestingly, the stress at a given strain in all the materials is linear as a function of strain rate indicating that there are no phase transformations affecting the response over the regime tested (Fig. 8).

Interestingly, polypropylene shows a markedly different behavior than PTFE and PE. Okereke et al. [92] showed that PP exhibited a distinct peak in true stress with subsequent strain softening, which they attribute to plastic strain-induced structural evolution of the non-crystalline portion of the polymer, which is approximately $35 \%$, in concert with adiabatic heating of the material. Additionally, the stress as a function of strain rate in this material exhibited a bilinear dependence on strain rate, which is not observed in PTFE or PE. This may be due to the glass transition moving to room temperature at high strain rates.

\section{Time-Temperature Superposition for Large Strain Response of Polymers}

The first extensive experimental studies on the temperature and rate dependence of glassy polymers (PMMA [16] and polycarbonate $[15,17,18,133])$ were conducted by Bauwens and Bauwens-Crowet et al. [15-18, 133]. This series of papers provided the first recognition of two molecular processes, which were responsible for the rate and temperature dependence of the yield strength in glass polymers. With this recognition, they were able to develop a master curve to allow for prediction of response outside of the experimentally tested regime. Similar research on polycarbonate (PC) was performed by Rietsch and Bouette [182], who extended the range of strain rates tested by
Fig. 7 Plasticized PVC a stress-strain relationship at different strain rates and b representative stress close to yield as a function of strain rate. Data from [153]
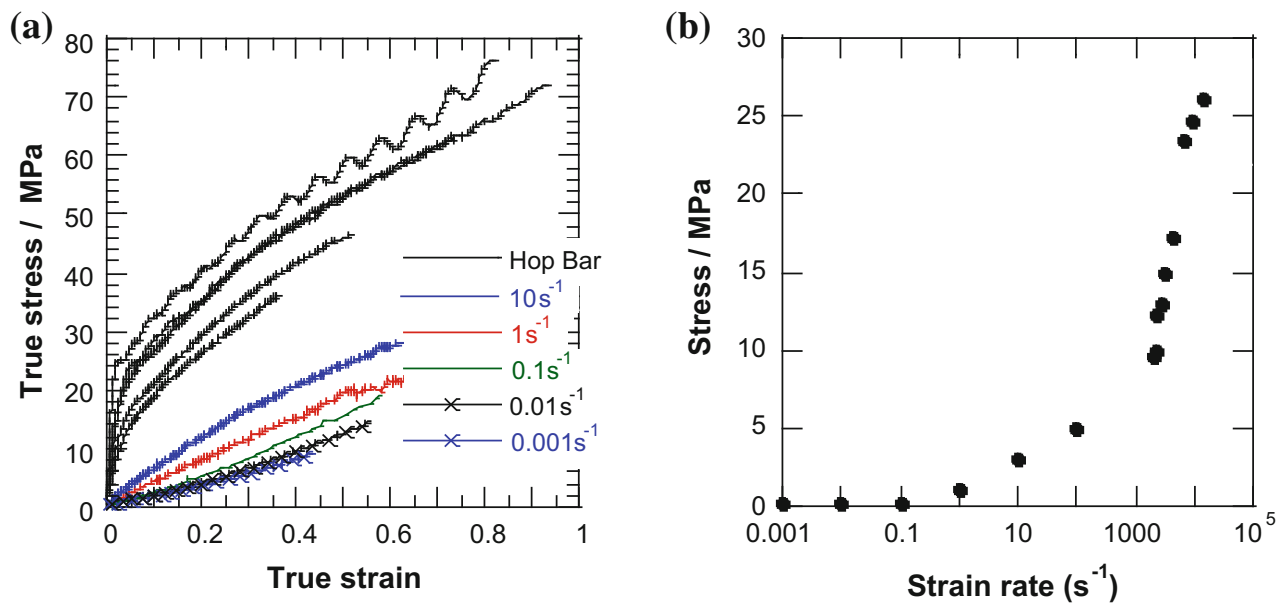
Fig. 8 a Stress versus strain rate for PTFE and $\mathbf{b}$ true stress at $15 \%$ strain versus strain rate from Jordan et al. [174], Walley and Field [5], and Rae and Dattelbaum [6], at room temperature

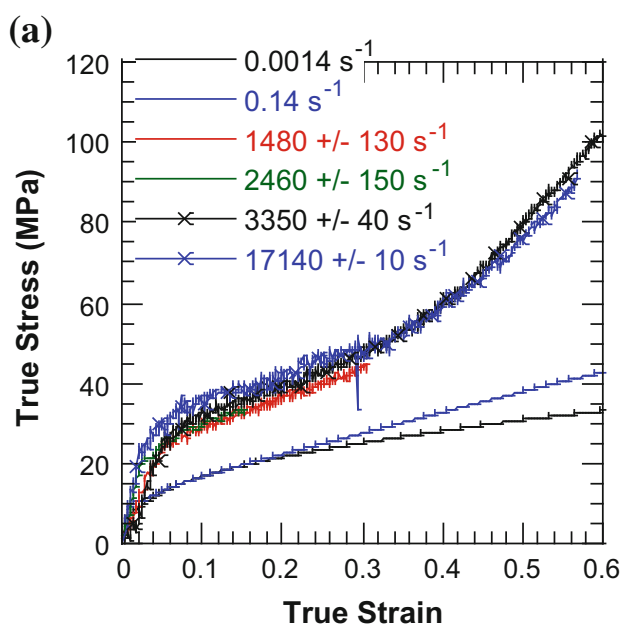

(b)

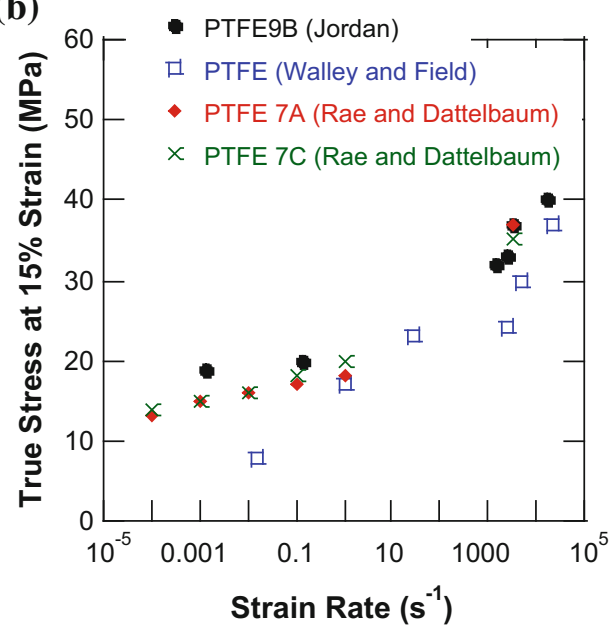

using a Split Hopkinson Pressure Bar (SHPB) and observed an increase in the rate dependence of the yield stress above approximately $100 \mathrm{~s}^{-1}$ at room temperature. Walley and Field [5] studied several polymers, focusing on rate-dependent behavior. The tests were conducted at strain rates ranging from $10^{-2}$ to $10^{4} \mathrm{~s}^{-1}$, using four different experimental techniques, including a direct impact Hopkinson bar for strain rates above $10^{3} \mathrm{~s}^{-1}$. For a significant proportion of polymers it was observed that yield stress increased more rapidly with increasing strain rate at higher rates. Such observations were subsequently made for a number of polymeric materials; however, some authors suggested that the observed response at high rate may have been an artifact of testing [183, 184], rather than an intrinsic property of the polymers under investigation.

It was partly to test such a hypothesis that Siviour et al. [19] reintroduced the use of time-temperature superposition equivalence as a means to interpret rate dependence in $\mathrm{PC}$ and polyvinylideneflouride (PVDF). The materials were characterized over a wide range of strain rates $\left(10^{-4}\right.$ to $10^{4} \mathrm{~s}^{-1}$ ) at room temperature and a wide range of temperatures $\left(-50\right.$ to $\left.150^{\circ} \mathrm{C}\right)$ at a constant strain rate $\left(10^{3}\right.$ $\mathrm{s}^{-1}$ ). The authors then posed an empirical formula for mapping the yield stress dependence on temperature to the dependence on strain rate, which agreed well with experimental data and comparisons in the literature. The formula employed a linear interdependence of temperature and strain rate, using reference strain rate and temperature as experimental constants, as well as the experimentally determined mapping parameter, $D$ :

$T=T_{0}+A\left(\log \dot{\varepsilon}_{0}-\log \dot{\varepsilon}\right)$

where $A$ quantifies the interaction between rate and temperature and maps from a temperature $T$ to a new temperature $T_{0}$ and mapping the strain rate from $\dot{\varepsilon}_{0}$ to a new strain rate $\dot{\varepsilon}$. The mapping parameter, $A$, may be considered as the temperature-strain rate equivalence parameter, which relates equivalent stress states in the material and is agnostic to the underlying deformation mechanisms [185] and it is typically found by fitting temperature dependent and rate dependent yield data but, in principle, should be obtainable from Dynamic Mechanical Analysis (DMA) data, and is certainly consistent with these data [153]. Siviour's formula was able to capture several changes deformation mechanisms which govern changes in yield stress, including the inflection in data which involves the glass transition PVDF, and that which is understood as the beginning of the $\beta$-transition in PC. This analysis has subsequently been used on semi-crystalline polymers [174, 178] and particulate composites [41, 186]. Recent data on PVC with different amounts of plasticizer [153] have shown the effects on the analysis of having two transitions influencing the rate dependence, and how this can be dealt with using two shift parameters, similar to the deconstruct, shift, reconstruct method pioneered by Mulliken and Boyce [20], discussed further below.

Brown et al. [178] provided a detailed analysis of the linear mapping proposed Siviour [19] starting in the context of polymers with linear rate and temperature dependence but drawing conclusions applicable to all polymers. In particular, they pointed out that, even if the rate dependent and temperature dependent data sets share a common point, with an intersection stress $\sigma_{\mathrm{X}}$, it is unlikely that the lines of best fit to these data sets will cross at this point: the lines may be globally suitable but are not pointwise accurate. This error can lead to instabilities in the evaluation of $A$, in particular if it is evaluated by pointwise comparison of the temperature and strain rate required to achieve a certain yield stress, around the intersection stress. Hence, in cases where $A$ must be evaluated in a pointwise manner, for example in cases where the temperature and strain rate dependence of the yield stress do not follow 
simple relationships, the points chosen should be as far as practicable from the intersection stress. Furthermore, they also discussed the difficulties in accurately extrapolating glass transition temperatures to high strain rates, where small uncertainties in $\mathrm{T}_{\mathrm{g}}$ can lead to relatively large changes in the strain rate at which its effects can be seen in rate dependent data.

One issue that must be considered when implementing time-temperature superposition in polymers is the effect of adiabatic heating, particularly at high strain rates [185]. At elevated strain rates, the conversion of plastic work to heat in the specimen can occur much faster than the heat can be dissipated away through the platens or other loading device. In this situation, the measured flow stress is the stress at the instantaneous temperature of the specimen rather than the global experimental temperature resulting in thermal softening, which is not truly representative of the material behavior. Adding to the difficulty of understanding adiabatic heating under dynamic loading is the lack of high speed thermal techniques. Only recently have thermal cameras with sufficient acquisition times become available [142, 187-189].

One disadvantage to the Siviour technique as discussed above [19] is that it is limited to mapping a single stress state, i.e. a point-wise mapping, usually of the yield stress. The work of Furmanski, Cady, and Brown [185] considered the full deformation response using a strain-rate jump technique to eliminate the adiabatic effects that can be seen in polymers at strain rates greater than $0.01 \mathrm{~s}^{-1}$ and $15 \%$ strain. The experiments involved rapidly increasing from low to intermediate $\left(1 \mathrm{~s}^{-1}\right)$ strain rates, deforming the specimen, and then allowing it to cool. Using this technique, which eliminates adiabatic effects, they observed that the Siviour relationship [19] can be used to map the whole stress strain curve, rather than a single point.

Another approach to using time-temperature superposition to better understand high rate behavior is not to attempt to achieve isothermal conditions by interrupting the experiment, which becomes increasingly difficult as the rate increases, but rather to mimic the adiabatic effects seen in dynamic loading in a low strain rate experiment. For example, to replicate loading at, say, $1500 \mathrm{~s}^{-1}$ and $25^{\circ} \mathrm{C}$, one may perform an experiment at $0.001 \mathrm{~s}^{-1}$ and an initial temperature of $-20{ }^{\circ} \mathrm{C}$, or whatever temperature is required to replicate the yield, typically achieved using an environmental chamber. As the loading progresses, the chamber temperature is raised according to the work done on the specimen, i.e.

$\Delta T(\varepsilon)=\frac{\int^{\varepsilon} \sigma d \varepsilon}{\rho c}$,

this replicates the temperature rise observed in an adiabatic high rate experiment, assuming that all of the mechanical work done on the specimen is converted to heat. Recently, Kendall and Siviour have shown that this approach faithfully allows the high rate behavior of PVC to be replicated in low rate experiments [94]. Furthermore, they have shown that whilst the high rate behavior of PC and PMMA can be replicated, this requires $\Delta T$ be modified from that predicted by the above equation, implying that there are further processes in these materials which affect the energy partition during deformation [124]. Finally, preliminary data have shown that this technique might prove effective in composite materials in which one component is temperature and rate dependent whilst the other is independent of these conditions [190].

Although not strictly applied to large strain response, when discussing the use of time-temperature superposition to understand the effect of lower order transitions on the high strain rate properties of polymers, mention should also be made of the deconstruct-shift-reconstruct method developed by Mulliken and Boyce [20] in order to predict the modulus of a polymer at high strain rate from low rate data in the case of multiple transitions with different frequency dependencies. Here, modulus-temperature data are split into components corresponding to the various transitions (e.g. $\alpha, \beta$ etc.) and the frequency dependence of the transitions is established. The transitions can then individually be shifted to high strain rate before being reconstructed to produce a new modulus-temperature dependence appropriate for high rate constitutive modeling.

\section{Pressure Effects in Polymers}

Although pressure effects can play a large role on the mechanical properties of polymers, there has been limited research into this topic, particularly recently. The first study where a polymer was loaded under hydrostatic pressure was conducted by Bridgman in 1953 [191]. In 1975, Pae and Bhateja [22] wrote a review of the effects of hydrostatic pressure on the mechanical behavior of polymers, including specific properties of the polymers that had been characterized to date. In their survey of materials, they found that while all polymers exhibit pressure dependent properties, some features are material specific, and some are observed across all polymers, namely that increasing hydrostatic pressure results in increased modulus and yield stress, sometimes by as much as $50-100 \%$. Increasing pressure in materials where the glass transition is below room temperature was found to shift the transition to room temperature, for example in LDPE [22], similar to time-temperature superposition. Due to the differences in underlying deformation mechanisms, the ductility and post yield behavior in polymers varies by material [22]. 
Table 1 Ratio of compressive to tensile yield strength for a range of polymers

\begin{tabular}{lll}
\hline Material & $\sigma_{C} / \sigma_{T}$ & References \\
\hline High density polyethylene (HDPE) & 1.0 & {$[198]$} \\
& 1.18 & {$[195]$} \\
Polycarbonate (PC) & 1.20 & {$[192]$} \\
& 1.11 & {$[18]$} \\
Polypropylene (PP) & 1.24 & {$[195]$} \\
Polyvinylchloride (PVC) & 1.33 & {$[192]$} \\
& 1.3 & {$[198]$} \\
\hline
\end{tabular}

The hydrostatic pressure dependence of yield in polymers has been observed by many authors [17, 192, 193]. The physical manifestation of this pressure dependence is a difference in tensile and compressive yield stress for the same material, as demonstrated for PVC in Fig. 6c. As shown in Table 1, these ratios are between 1 and 1.4 for a variety of polymeric materials, where a ratio of 1 indicates that the material is nominally pressure insensitive. Several yield criteria have been used to describe the yield behavior in polymers with the similarity between them being that the yield stress displays a linear dependence on hydrostatic pressure [194-197].

\section{Summary}

The temperature, pressure, and strain rate dependence of polymers has been of interest from the earliest days of high strain rate testing. Although these materials present experimental challenges that are not of concern for metallic specimens, especially for high strain rate characterization, a large number of studies have been performed producing a high quality experimental database for amorphous, semicrystalline and rubbery polymer materials. A key property of polymers which distinguishes them from metals is the time-temperature superposition effect, namely that increases in the strain rate or frequency of the applied loading have the same effect as decreases in temperature. This is a well-established effect for polymer modulus and associated behavior, and, for example, has been described by the WLF and Arrhenius equations; it can also be described by the deconstruct-shift-reconstruct method. Over the past 40 years, since the first papers investigating rate and temperature dependence of yield stress by Bauwens and Bauwens-Crowet, there has been development in understanding of time-temperature superposition as a tool for understanding large strain behavior under dynamic conditions. A linear mapping between strain rate and temperature is sufficient if only one transition is involved, and can be used to describe both yield and post-yield behavior. For polymers in which the rate dependence is affected by more than one transition, further mappings may be required. In an extension to this technique, the effects of the change from isothermal to adiabatic conditions as the strain rate increases can also be replicated by suitable temperature profiling. These techniques offer the potential for better understanding of the underlying mechanisms governing high rate behavior in the future.

Acknowledgments Dr. Siviour would like to thank the following people with whom he has performed polymer research over the past 12 years: JE Field, SM Walley, WG Proud, DM Williamson, S Palmer, M Kendall, B Mortimer, DR Drodge, S-H Yoon, Y Huang, X Tang, J Foley, R Froud, and R Duffin. He also acknowledges the financial support of the Air Force Office of Scientific Research (AFOSR), Engineering and Physical Sciences Research Council (EPSRC), and Pembroke College, Oxford. Dr. Jordan would like to thank the following people who have made her polymer research possible: JR Foley, G Sunny, EN Brown, JE Spowart, MJ Kendall, EB Herbold, and BT Woodworth. She would like to thank the Air Force Research Laboratory (Munitions Directorate and AFOSR) for supporting her research over the last 12 years.

\section{References}

1. Kolsky H (1949) An investigation of the mechanical properties of materials at very high rates of loading. Proc Phys Soc Lond Sect B 62(11):676-700

2. Davies E, Hunter S (1963) The dynamic compression testing of solids by the method of the split Hopkinson pressure bar. J Mech Phys Solids 11(3):155-179

3. Walley S, Field J, Pope R, Safford N (1991) The rapid deformation behaviour of various polymers. J Phys III 1(12): 1889-1925

4. Walley S, Field J, Pope P, Safford N (1989) A study of the rapid deformation behaviour of a range of polymers. Philos Trans R Soc Lond A Math Phys Eng Sci 328(1597):1-33

5. Walley S, Field J (1994) Strain rate sensitivity of polymers in compression from low to high rates. DYMAT j 1(3):211-227

6. Rae PJ, Dattelbaum DM (2004) The properties of poly(tetrafluoroethylene) (PTFE) in compression. Polymer 45(22):7615-7625

7. Brown EN, Rae PJ, Orler EB (2006) The influence of temperature and strain rate on the constitutive and damage responses of polychlorotrifluoroethylene (PCTFE, Kel-F 81). Polymer 47(21):7506-7518

8. Brown EN, Rae PJ, Bruce Orler E, Gray Iii GT, Dattelbaum DM (2006) The effect of crystallinity on the fracture of polytetrafluoroethylene (PTFE). Mater Sci Eng C 26(8):1338-1343

9. Brown E, Trujillo C, Gray G III, Rae P, Bourne N (2007) Soft recovery of polytetrafluoroethylene shocked through the crystalline phase II-III transition. J Appl Phys 101(2):024916

10. Rae PJ, Brown EN (2005) The properties of poly(tetrafluoroethylene) (PTFE) in tension. Polymer 46(19):8128-8140

11. Rae PJ, Brown EN, Clements BE, Dattelbaum DM (2005) Pressure-induced phase change in poly (tetrafluoroethylene) at modest impact velocities. J Appl Phys 98(6):063521

12. Bourne N, Brown E, Millett J, Gray G III (2008) Shock, release and Taylor impact of the semicrystalline thermoplastic polytetrafluoroethylene. J Appl Phys 103(7):074902

13. Shergold OA, Fleck NA, Radford D (2006) The uniaxial stress versus strain response of pig skin and silicone rubber at low and high strain rates. Int J Impact Eng 32(9):1384-1402 
14. Williams ML, Landel RF, Ferry JD (1955) The temperature dependence of relaxation mechanisms in amorphous polymers and other glass-forming liquids. J Am Chem Soc 77(14): 3701-3707

15. Bauwens J, Bauwens-Crowet C, Homes G (1969) Tensile yieldstress behavior of poly (vinyl chloride) and polycarbonate in the glass transition region. J Polym Sci A-2 Poly Phys 7(10): $1745-1754$

16. Bauwens-Crowet C (1973) The compression yield behaviour of polymethyl methacrylate over a wide range of temperatures and strain-rates. J Mater Sci 8(7):968-979

17. Bauwens-Crowet C, Bauwens J, Homes G (1969) Tensile yieldstress behavior of glassy polymers. J Polym Sci A-2 Poly Phys 7(4):735-742

18. Bauwens-Crowet C, Bauwens J-C, Homes G (1972) The temperature dependence of yield of polycarbonate in uniaxial compression and tensile tests. J Mater Sci 7(2):176-183

19. Siviour CR, Walley SM, Proud WG, Field JE (2005) The high strain rate compressive behaviour of polycarbonate and polyvinylidene difluoride. Polymer 46(26):12546-12555

20. Mulliken AD, Boyce MC (2006) Mechanics of the rate-dependent elastic-plastic deformation of glassy polymers from low to high strain rates. Int J Solids Struct 43(5):1331-1356

21. Sauer J (1977) Deformation, yield and fracture of polymers at high pressure. Polym Eng Sci 17(3):150-164

22. Pae K, Bhateja S (1975) The effects of hydrostatic pressure on the mechanical behavior of polymers. J Macromol Sci Rev Macromol Chem 13(1):1-75

23. Gerlach R, Siviour CR, Petrinic N, Wiegand J (2008) Experimental characterisation and constitutive modelling of RTM-6 resin under impact loading. Polymer 49(11):2728-2737

24. Ree T, Eyring H (1955) Theory of non-newtonian flow. I. Solid plastic system. J Appl Phys 26(7):793-800

25. Haward R, Thackray G (1968) The use of a mathematical model to describe isothermal stress-strain curves in glassy thermoplastics. Proc R Soc Lond A 302(1471):453-472

26. Anand L, Ames N (2006) On modeling the micro-indentation response of an amorphous polymer. Int J Plast 22(6):1123-1170

27. Arruda EM, Boyce MC (1993) Evolution of plastic anisotropy in amorphous polymers during finite straining. Int J Plast 9(6): 697-720

28. Bergström J, Boyce M (1998) Constitutive modeling of the large strain time-dependent behavior of elastomers. J Mech Phys Solids 46(5):931-954

29. Boyce MC, Parks DM, Argon AS (1988) Large inelastic deformation of glassy polymers. Part I: rate dependent constitutive model. Mech Mater 7(1):15-33

30. Foreman JP, Porter D, Behzadi S, Curtis PT, Jones FR (2010) Predicting the thermomechanical properties of an epoxy resin blend as a function of temperature and strain rate. Compos A Appl Sci Manuf 41(9):1072-1076

31. Porter D, Gould PJ (2009) Predictive nonlinear constitutive relations in polymers through loss history. Int J Solids Struct 46(9):1981-1993

32. Porter D, Gould P (2006) A general equation of state for polymeric materials. J Phys IV 134:373-378

33. Porter D (1996) Materials modelling: a bridge from atoms to bulk properties. Adv Perform Mater 3(3-4):309-324

34. Porter D (1995) Group interaction modelling of polymer properties. Marcel Dekker, New York

35. Chen WW (2016) Experimental methods for characterizing dynamic response of soft materials. J Dyn Behav Mater. doi:10. 1007/s40870-016-0047-5

36. Field J, Walley S, Proud W, Goldrein H, Siviour C (2004) Review of experimental techniques for high rate deformation and shock studies. Int J Impact Eng 30(7):725-775
37. Kirkaldy D (1862) Results of an experimental inquiry into the comparative tensile strength and other properties of various kinds of wrought-iron and steel. Hamilton, Adams, \& Co, London

38. Dunn BW (1897) A photographic impact testing machine for measuring the varying intensity of an impulsive force. J Franklin Inst 144(5):321-348

39. Roland C (2006) Mechanical behavior of rubber at high strain rates. Rubber Chem Technol 79(3):429-459

40. Roland CM, Twigg JN, Vu Y, Mott PH (2007) High strain rate mechanical behavior of polyurea. Polymer 48(2):574-578

41. Williamson D, Siviour C, Proud W, Palmer S, Govier R, Ellis K, Blackwell P, Leppard C (2008) Temperature-time response of a polymer bonded explosive in compression (EDC37). J Phys D Appl Phys 41(8):085404

42. Cai J, Walley S, Hunt R, Proud W, Nesterenko V, Meyers M (2008) High-strain, high-strain-rate flow and failure in PTFE/Al/ W granular composites. Mater Sci Eng A 472(1):308-315

43. Dannis M, Watling R (1966) Stress-strain properties of plastics at high strain rates. Rev Sci Instrum 37(12):1716-1721

44. Ramon O, Mizrahi S, Miltz J (1994) Merits and limitations of the drop and shock tests in evaluating the dynamic properties of plastic foams. Polym Eng Sci 34(18):1406-1410

45. Swallowe G, Lee $S$ (2003) A study of the mechanical properties of PMMA and PS at strain rates of $10^{-4}$ to $10^{3}$ over the temperature range 293-363 K. In: Journal de Physique IV (proceedings). EDP Sciences, pp 33-38

46. Lee S, Swallowe G (2004) Direct measurement of high rate stress-strain curves using instrumented falling weight and highspeed photography. Imaging Sci J 52(4):193-201

47. Trautmann A, Siviour C, Walley S, Field J (2005) Lubrication of polycarbonate at cryogenic temperatures in the split Hopkinson pressure bar. Int J Impact Eng 31(5):523-544

48. Balzer J, Siviour C, Walley S, Proud W, Field J (2004) Behaviour of ammonium perchlorate-based propellants and a polymer-bonded explosive under impact loading. Proc R Soc Lond A Math Phys Eng Sci 460(2043):781-806

49. Viot P, Beani F, Lataillade J-L (2005) Polymeric foam behavior under dynamic compressive loading. J Mater Sci 40(22): $5829-5837$

50. Foot J, Truss R, Ward I, Duckett R (1987) The yield behaviour of amorphous polyethylene terephthalate: an activated rate theory approach. J Mater Sci 22(4):1437-1442

51. Al-Maliky N, Parry D (1996) A freely expanding ring technique for measuring the tensile properties of polymers. Meas Sci Technol 7(5):746-752

52. Scarpa F, Ciffo L, Yates J (2004) Dynamic properties of high structural integrity auxetic open cell foam. Smart Mater Struct 13(1):49-56

53. Song B, Syn C, Grupido C, Chen W, Lu W-Y (2008) A long split Hopkinson pressure bar (LSHPB) for intermediate-rate characterization of soft materials. Exp Mech 48(6):809-815

54. Cloete T, Oxtoby S (2009) A new technique for compression tests at intermediate strain rates: prototype results. In: DYMAT-international conference on the mechanical and physical behaviour of materials under dynamic loading. EDP Sciences, pp 249-255

55. Gray GT (2000) Classic split-hopkinson pressure bar testing. ASM International, Materials Park, OH, pp 462-476

56. Gray G, Blumenthal WR (2000) Split-hopkinson pressure bar testing of soft materials. ASM International, Materials Park, $\mathrm{OH}$, pp 488-496

57. Chen WW, Song B (2010) Split Hopkinson (Kolsky) bar: design, testing and applications. Springer, Berlin

58. Ramesh KT (2008) High rates and impact experiments. In: Sharpe Jr., William N (eds) Springer handbook of experimental solid mechanics. Springer, Berlin, pp 929-960 
59. Casem D, Grunschel S, Schuster B (2012) Normal and transverse displacement interferometers applied to small diameter Kolsky bars. Exp Mech 52(2):173-184

60. Jia D, Ramesh K (2004) A rigorous assessment of the benefits of miniaturization in the Kolsky bar system. Exp Mech 44(5): $445-454$

61. Casem DT, Zellner MB (2013) Kolsky bar wave separation using a photon doppler velocimeter. Exp Mech 53(8):1467-1473

62. Chen W, Lu F, Zhou B (2000) A quartz-crystal-embedded split Hopkinson pressure bar for soft materials. Exp Mech 40(1):1-6

63. Wasley RJ, Hoge KG, Cast JC (1969) Combined strain gaugequartz crystal instrumented hopkinson split bar. Rev Sci Instrum 40(7):889-894

64. Kendall MJ, Drodge DR, Froud RF, Siviour CR (2014) Stress gage system for measuring very soft materials under high rates of deformation. Meas Sci Technol 25(7):075603

65. Lea LJ, Jardine AP (2015) Two-wave photon Doppler velocimetry measurements in direct impact Hopkinson pressure bar experiments. In: EPJ web of conferences. EDP Sciences, p 01063

66. Chen W, Lu F, Frew D, Forrestal M (2002) Dynamic compression testing of soft materials. J Appl Mech 69(3):214-223

67. Siviour CR (2005) High strain rate properties of materials using Hopkinson bar techniques. PhD Thesis, University of Cambridge

68. Briscoe B, Nosker R (1984) The influence of interfacial friction on the deformation of high density polyethylene in a split Hopkinson pressure bar. Wear 95(3):241-262

69. Pochhammer L (1876) Ueber die Fortpflanzungsgeschwindigkeiten kleiner Schwingungen in einem unbegrenzten isotropen Kreiscylinder. Journal für die reine und angewandte Mathematik $81: 324-336$

70. Chree C (1886) Longitudinal vibrations of a circular bar. Quart J Pure Appl Math 21:287-298

71. Gorham D (1983) A numerical method for the correction of dispersion in pressure bar signals. J Phys E Sci Instrum 16(6): 477-479

72. Johnson TPM, Sarva SS, Socrate S (2010) Comparison of low impedance split-hopkinson pressure bar techniques in the characterization of polyurea. Exp Mech 50(7):931-940

73. Chen WW, Song B (2010) Dynamic characterization of soft materials. In: Shukla A, Ravichandran G, Rajapakse YDS (eds) Dynamic failure of materials and structures. Springer, New York, pp 1-28

74. Jordan JL, Foley JR, Siviour CR (2008) Mechanical properties of Epon 826/DEA epoxy. Mech Time-Depend Mater 12(3): 249-272

75. Nie X, Song B, Ge Y, Chen WW, Weerasooriya T (2009) Dynamic tensile testing of soft materials. Exp Mech 49(4): 451-458

76. Chen W, Zhang B, Forrestal MJ (1999) A split Hopkinson bar technique for low-impedance materials. Exp Mech 39(2):81-85

77. Zhao H, Gary G, Klepaczko JR (1997) On the use of a viscoelastic split Hopkinson pressure bar. Int J Impact Eng 19(4):319-330

78. Bacon C (1998) An experimental method for considering dispersion and attenuation in a viscoelastic Hopkinson bar. Exp Mech 38(4):242-249

79. Casem DT, Fourney W, Chang P (2003) Wave separation in viscoelastic pressure bars using single-point measurements of strain and velocity. Polym Testing 22(2):155-164

80. Zhao H, Gary G (1995) A three dimensional analytical solution of the longitudinal wave propagation in an infinite linear viscoelastic cylindrical bar. Application to experimental techniques. J Mech Phys Solids 43(8):1335-1348

81. Wang L, Labibes K, Azari Z, Pluvinage G (1994) Generalization of split Hopkinson bar technique to use viscoelastic bars. Int $\mathbf{J}$ Impact Eng 15(5):669-686
82. Sawas O, Brar NS, Brockman R (1998) Dynamic characterization of compliant materials using an all-polymeric split Hopkinson bar. Exp Mech 38(3):204-210

83. Morin D, Haugou G, Lauro F, Bennani B, Bourel B (2015) Elasto-viscoplasticity behaviour of a structural adhesive under compression loadings at low, moderate and high strain rates. J Dyn Behav Mater 1(2):124-135

84. Aleyaasin M, Harrigan J (2010) Wave dispersion and attenuation in viscoelastic polymeric bars: analysing the effect of lateral inertia. Int J Mech Sci 52(5):754-757

85. Ahonsi B, Harrigan JJ, Aleyaasin M (2012) On the propagation coefficient of longitudinal stress waves in viscoelastic bars. Int J Impact Eng 45:39-51

86. Butt HSU, Xue P (2014) Determination of the wave propagation coefficient of viscoelastic SHPB: significance for characterization of cellular materials. Int J Impact Eng 74:83-91

87. Butt H, Xue P, Jiang T, Wang B (2015) Parametric identification for material of viscoelastic SHPB from wave propagation data incorporating geometrical effects. Int J Mech Sci 91:46-54

88. Salisbury CP, Cronin DS (2009) Mechanical properties of ballistic gelatin at high deformation rates. Exp Mech 49(6): 829-840

89. Song B, Chen W (2004) Dynamic stress equilibration in split Hopkinson pressure bar tests on soft materials. Exp Mech 44(3):300-312

90. Song B, Ge Y, Chen W, Weerasooriya T (2007) Radial inertia effects in Kolsky bar testing of extra-soft specimens. Exp Mech 47(5):659-670

91. Gorham D (1991) The effect of specimen dimensions on high strain rate compression measurements of copper. J Phys D Appl Phys 24(8):1489-1492

92. Okereke MI, Buckley CP, Siviour CR (2012) Compression of polypropylene across a wide range of strain rates. Mech TimeDepend Mater 16(4):361-379

93. Hartley RS, Cloete TJ, Nurick GN (2007) An experimental assessment of friction effects in the split Hopkinson pressure bar using the ring compression test. Int J Impact Eng 34(10): $1705-1728$

94. Kendall MJ, Siviour CR (2013) Experimentally simulating adiabatic conditions: approximating high rate polymer behavior using low rate experiments with temperature profiles. Polymer 54(18):5058-5063

95. Chou S, Robertson K, Rainey J (1973) The effect of strain rate and heat developed during deformation on the stress-strain curve of plastics. Exp Mech 13(10):422-432

96. Arruda EM, Boyce MC, Jayachandran R (1995) Effects of strain rate, temperature and thermomechanical coupling on the finite strain deformation of glassy polymers. Mech Mater 19(2):193-212

97. Garg M, Mulliken A, Boyce M (2008) Temperature rise in polymeric materials during high rate deformation. J Appl Mech 75(1):011009

98. Hillmansen S, Haward RN (2001) Adiabatic failure in polyethylene. Polymer 42(22):9301-9312

99. Hillmansen S, Hobeika S, Haward R, Leevers P (2000) The effect of strain rate, temperature, and molecular mass on the tensile deformation of polyethylene. Polym Eng Sci 40(2): 481-489

100. Li Z, Lambros J (2001) Strain rate effects on the thermomechanical behavior of polymers. Int J Solids Struct 38(20): 3549-3562

101. Bjerke T, Li Z, Lambros J (2002) Role of plasticity in heat generation during high rate deformation and fracture of polycarbonate. Int J Plast 18(4):549-567

102. Taylor G (1946) James Forrest lecture 1946. The testing of materials at high rates of loading. J Inst Civil Eng 26(8): 486-519 
103. Taylor G (1948) The use of flat-ended projectiles for determining dynamic yield stress. I. Theoretical considerations. Proc R Soc Lond A Math Phys Eng Sci 194(1038):289-299

104. Whiffin A (1947) The use of flat-ended projectiles for determining dynamic yield stress. II. Tests on various metallic materials. Proc R Soc Lond A Math Phys Eng Sci 194(1038):300-322

105. Carrington W, Gayler ML (1948) The use of flat-ended projectiles for determining dynamic yield stress. III. Changes in microstructure caused by deformation under impact at highstriking velocities. Proc R Soc Lond A Math Phys Eng Sci 194(1038):323-331

106. Briscoe BJ, Hutchings IM (1976) Impact yielding of high density polyethylene. Polymer 17(12):1099-1102

107. Hutchings I (1978) Estimation of yield stress in polymers at high strain-rates using GI Taylor's impact technique. J Mech Phys Solids 26(5):289-301

108. Brown EN, Trujillo CP, Gray GT (2007) Influence of polyethylene molecular conformation on taylor impact measurements: a comparison of HDPE, UHMPE, and PEX. AIP Conf Proc 955(1):691-694

109. Millett JCF, Bourne NK, Stevens GS (2006) Taylor impact of polyether ether ketone. Int J Impact Eng 32(7):1086-1094

110. Sarva S, Mulliken AD, Boyce MC (2007) Mechanics of Taylor impact testing of polycarbonate. Int $\mathrm{J}$ Solids Struct 44(7-8):2381-2400

111. Rae PJ, Brown EN, Orler EB (2007) The mechanical properties of poly(ether-ether-ketone) (PEEK) with emphasis on the large compressive strain response. Polymer 48(2):598-615

112. Shin H-S, Park S-T, Kim S-J, Choi J-H, Kim J-T (2008) Deformation behavior of polymeric materials by taylor impact. Int J Mod Phys B 22(09n11):1235-1242

113. Cho H, Bartyczak S, Mock W Jr, Boyce MC (2013) Dissipation and resilience of elastomeric segmented copolymers under extreme strain rates. Polymer 54(21):5952-5964

114. Resnyansky AD, Bourne NK, Brown EN, Millett JCF, Rae PJ, McDonald SA, Withers PJ (2014) Phase transition modeling of polytetrafluoroethylene during Taylor impact. J Appl Phys 116(22):223502

115. Cao F, Cerreta E, Trujillo C, Gray G (2008) Dynamic tensile extrusion response of tantalum. Acta Mater 56(19):5804-5817

116. Gray III G, Cerreta E, Yablinsky C, Addessio L, Henrie B, Sencer B, Burkett M, Maudlin P, Maloy S, Trujillo C (2006) Influence of shock prestraining and grain size on the dynamictensile-extrusion response of copper: experiments and simulation. In: Shock compression of condensed matter-2005: proceedings of the conference of the american physical society topical group on shock compression of condensed matter. AIP Publishing, pp 725-728

117. Furmanski J, Trujillo CP, Martinez DT, Gray GT III, Brown EN (2012) Dynamic-Tensile-Extrusion for investigating large strain and high strain rate behavior of polymers. Polym Testing 31(8):1031-1037

118. Trujillo CP, Brown EN, Gray III G (2011) Dynamic-tensileextrusion response of polytetrafluoroethylene (PTFE) and polychlorotrifluoroethylene (PCTFE). In: Dynamic behavior of materials, vol 1. Springer, Berlin, pp 73-75

119. Brown EN, Gray III G, Trujillo CP (2009) Influence of necking propensity on the dynamic-tensile-extrusion response of fluoropolymers. In: DYMAT-international conference on the mechanical and physical behaviour of materials under dynamic loading. EDP Sciences, pp 171-177

120. Furmanski J, Cady C, Rae P, Trujillo CP, Gray III GT, Brown E (2012) Dynamic-tensile-extrusion of polyurea. In: AIP conference proceedings. pp 1085-1088
121. Brown E, Furmanski J, Ramos K, Dattelbaum D, Jensen B, Iverson A, Carlson C, Fezzaa K, Gray III G, Patterson B (2014) High-density polyethylene damage at extreme tensile conditions. In: Journal of physics: conference series. IOP Publishing, p 112011

122. Furmanski J, Brown EN, Gray III GT, Trujillo C, Martinez DT, Bilyk S, Becker R (2014) Extreme tensile damage and failure in glassy polymers via dynamic-tensile-extrusion. In: Dynamic behavior of materials, vol 1. Springer, Berlin, pp 107-112

123. Acharya S, Mukhopadhyay AK (2013) High strain rate compressive behavior of PMMA. Polym Bull 71(1):1-17

124. Kendall M, Siviour C (2015) Experimentally simulating highrate behaviour: rate and temperature effects in polycarbonate and PMMA. Philos Trans R Soc A Math Phys Eng Sci 2014(372):20130202

125. Moy P, Weerasooriya T, Chen W, Hsieh A (2003) Dynamic stress-strain response and failure behavior of PMMA. In: ASME 2003 international mechanical engineering congress and exposition. ASME

126. Richeton J, Ahzi S, Daridon L, Rémond Y (2005) A formulation of the cooperative model for the yield stress of amorphous polymers for a wide range of strain rates and temperatures. Polymer 46(16):6035-6043

127. Foster M, Love B, Kaste R, Moy P (2015) The rate dependent tensile response of polycarbonate and poly-methylmethacrylate. J Dyn Behav Mater 1(2):162-175

128. Jordan JL, Spowart JE, Kendall MJ, Woodworth B, Siviour CR (2014) Mechanics of particulate composites with glassy polymer binders in compression. Philos Trans R Soc Lond A Math Phys Eng Sci 372(2015):20130215

129. Rittel D, Brill A (2008) Dynamic flow and failure of confined polymethylmethacrylate. J Mech Phys Solids 56(4):1401-1416

130. Richeton J, Ahzi S, Vecchio K, Jiang F, Adharapurapu R (2006) Influence of temperature and strain rate on the mechanical behavior of three amorphous polymers: characterization and modeling of the compressive yield stress. Int J Solids Struct 43(7):2318-2335

131. Hasan OA, Boyce MC (1995) A constitutive model for the nonlinear viscoelastic viscoplastic behavior of glassy polymers. Polym Eng Sci 35(4):331-344

132. Swallowe G, Lee S (2006) Quasi-static and dynamic compressive behaviour of poly (methyl methacrylate) and polystyrene at temperatures from 293 K to 363 K. J Mater Sci 41(19):6280-6289

133. Bauwens J (1972) Relation between the compression yield stress and the mechanical loss peak of bisphenol-A-polycarbonate in the $\beta$ transition range. J Mater Sci 7(5):577-584

134. Fu S, Wang Y, Wang Y (2009) Tension testing of polycarbonate at high strain rates. Polym Test 28(7):724-729

135. Sarva S, Boyce MC (2007) Mechanics of polycarbonate during high-rate tension. J Mech Mater Struct 2(10):1853-1880

136. Nakai K, Yokoyama T (2015) Uniaxial compressive response and constitutive modeling of selected polymers over a wide range of strain rates. J Dyn Behav Mater 1(1):15-27

137. Kendall M, Siviour C (2012) Strain rate dependence in plasticized and un-plasticized PVC. In: EPJ web of conferences. EDP Sciences, p 02009

138. Jordan JL, Siviour C, Woodworth B (2012) High strain rate tensile and compressive effects in glassy polymers. EPJ Web Conf 26:01001

139. Gilat A, Goldberg RK, Roberts GD (2007) Strain rate sensitivity of epoxy resin in tensile and shear loading. J Aerosp Eng 20(2):75-89

140. Chen W, Zhang X (1997) Dynamic response of Epon 828/T-403 under multiaxial loading at various temperatures. J Eng Mater Technol 119(3):305-308 
141. Chen W, Zhou B (1998) Constitutive behavior of Epon 828/T403 at various strain rates. Mech Time-Depend Mater 2(2): $103-111$

142. Kendall MJ, Froud RF, Siviour CR (2014) Novel temperature measurement method \& thermodynamic investigations of amorphous polymers during high rate deformation. Polymer 55(10):2514-2522

143. Follansbee P, Kocks U (1988) A constitutive description of the deformation of copper based on the use of the mechanical threshold stress as an internal state variable. Acta Metall 36(1):81-93

144. Armstrong R, Walley S (2008) High strain rate properties of metals and alloys. Int Mater Rev 53(3):105-128

145. Jordan JL, Siviour CR, Sunny G, Bramlette C, Spowart JE (2013) Strain rate-dependant mechanical properties of OFHC copper. J Mater Sci 48(20):7134-7141

146. Gorham D (1989) Specimen inertia in high strain-rate compression. J Phys D Appl Phys 22(12):1888-1893

147. Forrestal M, Wright T, Chen W (2007) The effect of radial inertia on brittle samples during the split Hopkinson pressure bar test. Int J Impact Eng 34(3):405-411

148. Zhao H, Gary G (1997) A new method for the separation of waves. Application to the SHPB technique for an unlimited duration of measurement. J Mech Phys Solids 45(7):1185-1202

149. Hiermaier S, Meenken T (2010) Characterization of low-impedance materials at elevated strain rates. J Strain Anal Eng Des 45(6):401-409

150. Chen R, Huang S, Xia K, Lu F (2009) A modified Kolsky bar system for testing ultrasoft materials under intermediate strain rates. Rev Sci Instrum 80(7):076108

151. Shim V, Yang L, Lim C, Law P (2004) A visco-hyperelastic constitutive model to characterize both tensile and compressive behavior of rubber. J Appl Polym Sci 92(1):523-531

152. Wang Y, Arruda EM, Przybylo PA (2001) Characterization and constitutive modeling of a plasticized poly (vinyl chloride) for a broad range of strain rates. Rubber Chem Technol 74(4): $560-573$

153. Kendall MJ, Siviour CR (2014) Rate dependence of poly(vinyl chloride), the effects of plasticizer and time-temperature superposition. Proc R Soc A Math Phys Eng Sci 470:20140012

154. Shim J, Mohr D (2009) Using split Hopkinson pressure bars to perform large strain compression tests on polyurea at low, intermediate and high strain rates. Int J Impact Eng 36(9): $1116-1127$

155. Yi J, Boyce MC, Lee GF, Balizer E (2006) Large deformation rate-dependent stress-strain behavior of polyurea and polyurethanes. Polymer 47(1):319-329

156. Sarva S, Deschanel S, Boyce MC, Chen W (2007) Stress-strain behavior of a polyurea and a polyurethane from low to high strain rates. Polymer 48(8):2208-2213

157. Qi HJ, Boyce MC (2005) Stress-strain behavior of thermoplastic polyurethanes. Mech Mater 37(8):817-839

158. Zhao J, Knauss W, Ravichandran G (2007) Applicability of the time-temperature superposition principle in modeling dynamic response of a polyurea. Mech Time-Depend Mater 11(3-4): 289-308

159. Rao S, Shim V, Quah S (1997) Dynamic mechanical properties of polyurethane elastomers using a nonmetallic Hopkinson bar. J Appl Polym Sci 66(4):619-631

160. Cady C, Blumenthal W, Gray G, Idar D (2006) Mechanical properties of plastic-bonded explosive binder materials as a function of strain-rate and temperature. Polym Eng Sci 46(6): 812-819

161. Siviour CR, Laity PR, Proud WG, Field J, Porter D, Church P, Gould P, Huntingdon-Thresher W (2003) High strain rate properties of a polymer-bonded sugar: their dependence on applied and internal constraints. Proc R Soc A Math Phys Eng Sci 464(2093):1229-1255

162. Doman DA, Cronin DS, Salisbury CP (2006) Characterization of polyurethane rubber at high deformation rates. Exp Mech 46(3):367-376

163. Forsberg F, Siviour CR (2009) 3D deformation and strain analysis in compacted sugar using x-ray microtomography and digital volume correlation. Meas Sci Technol 20(9):095703

164. Niemczura J, Ravi-Chandar K (2011) On the response of rubbers at high strain rates-I. Simple waves. J Mech Phys Solids 59(2):423-441

165. Niemczura J, Ravi-Chandar K (2011) On the response of rubbers at high strain rates-II. Shock waves. J Mech Phys Solids 59(2):442-456

166. Niemczura J, Ravi-Chandar K (2011) On the response of rubbers at high strain rates-III. Effect of hysteresis. J Mech Phys Solids 59(2):457-472

167. Pierron F, Zhu H, Siviour C (2014) Beyond Hopkinson's bar. Philos Trans R Soc Lond A Math Phys Eng Sci 372(2023): 20130195

168. Yoon S-H, Giannakopoulos I, Siviour C (2015) Application of the Virtual Fields Method to the uniaxial behaviour of rubbers at medium strain rates. Int J Solids Struct 69-70:553-568

169. Yoon S-H, Winters M, Siviour C (2015) High strain-rate tensile characterization of EPDM rubber using non-equilibrium loading and the virtual fields method. Exp Mech. doi:10.1007/s11340015-0068-3

170. Wang Y, Arruda EM (2006) Constitutive modeling of a thermoplastic olefin over a broad range of strain rates. J Eng Mater Technol 128(4):551-558

171. Gómez-del Río T, Rodríguez J (2010) Compression yielding of polypropylenes above glass transition temperature. Eur Polymer J 46(6):1244-1250

172. Brown EN, Dattelbaum DM, Brown DW, Rae PJ, Clausen B (2007) A new strain path to inducing phase transitions in semicrystalline polymers. Polymer 48(9):2531-2536

173. Brown EN, Rae PJ, Dattelbaum DM, Clausen B, Brown DW (2008) In-situ measurement of crystalline lattice strains in polytetrafluoroethylene. Exp Mech 48(1):119-131

174. Jordan JL, Siviour CR, Foley JR, Brown EN (2007) Compressive properties of extruded polytetrafluoroethylene. Polymer 48(14):4184-4195

175. Gray III G, Cady C, Blumenthal W (1998) Influence of temperature and strain rate on the constitutive behavior of Teflon and nylon. In: Plasticity, pp 955-958

176. Brown EN, Dattelbaum DM (2005) The role of crystalline phase on fracture and microstructure evolution of polytetrafluoroethylene (PTFE). Polymer 46(9):3056-3068

177. Brown E, Rae P, Gray G (2006) The influence of temperature and strain rate on the tensile and compressive constitutive response of four fluoropolymers. In: Journal de Physique IV (proceedings). EDP Sciences, pp 935-940

178. Brown EN, Willms RB, Gray Iii GT, Rae PJ, Cady CM, Vecchio KS, Flowers J, Martinez MY (2007) Influence of molecular conformation on the constitutive response of polyethylene: a comparison of HDPE, UHMWPE, and PEX. Exp Mech 47(3):381-393

179. Starkweather HW Jr (1979) Comparison of the rheological properties of polytetrafluoroethylene below its melting point with certain low-molecular smectic states. J Polym Sci Polym Phys Ed 17(1):73-79

180. McCrum NG, Read BE, Williams G (1967) Anelastic and dielectric effects in polymeric solids. Wiley, New York

181. Bergström J, Hilbert L Jr (2005) A constitutive model for predicting the large deformation thermomechanical behavior of fluoropolymers. Mech Mater 37(8):899-913 
182. Rietsch F, Bouette B (1990) The compression yield behaviour of polycarbonate over a wide range of strain rates and temperatures. Eur Polym J 26(10):1071-1075

183. Dioh N, Leevers P, Williams J (1993) Thickness effects in split Hopkinson pressure bar tests. Polymer 34(20):4230-4234

184. Dioh N, Ivankovic A, Leevers P, Williams J (1994) The high strain rate behaviour of polymers. Le Journal de Physique IV 4(C8):C8-119-C118-124

185. Furmanski J, Cady CM, Brown EN (2013) Time-temperature equivalence and adiabatic heating at large strains in high density polyethylene and ultrahigh molecular weight polyethylene. Polymer 54(1):381-390

186. Thompson DG, Deluca R, Brown GW (2012) Time-temperature analysis, tension and compression in PBXs. J Energ Mater 30(4):299-323

187. Walley S, Proud W, Rae P, Field J (2000) Comparison of two methods of measuring the rapid temperature rises in split Hopkinson bar specimens. Rev Sci Instrum 71(4):1766-1771

188. Zehnder AT, Guduru PR, Rosakis AJ, Ravichandran G (2000) Million frames per second infrared imaging system. Rev Sci Instrum 71(10):3762-3768

189. Guduru P, Zehnder A, Rosakis A, Ravichandran G (2001) Dynamic full field measurements of crack tip temperatures. Eng Fract Mech 68(14):1535-1556

190. Kendall MJ, Siviour CR (2015) Experimentally simulating high rate composite deformation in tension and compression: polymer bonded explosive simulant. J Dyn Behav Mater 1(2):114-123

191. Bridgman P (1953) The effect of pressure on the tensile properties of several metals and other materials. J Appl Phys 24(5):560-570

192. Raghava R, Caddell RM, Yeh GSY (1973) The macroscopic yield behaviour of polymers. J Mater Sci 8(2):225-232

193. Bowden P, Jukes J (1972) The plastic flow of isotropic polymers. J Mater Sci 7(1):52-63

194. Bardia P, Narasimhan R (2006) Characterisation of pressuresensitive yielding in polymers. Strain 42(3):187-196

195. Donato GHB, Bianchi M (2012) Pressure dependent yield criteria applied for improving design practices and integrity assessments against yielding of engineering polymers. J Mater Res Technol 1(1):2-7

196. Farrokh B, Khan AS (2010) A strain rate dependent yield criterion for isotropic polymers: low to high rates of loading. Eur $\mathbf{J}$ Mech A Solids 29(2):274-282

197. Quinson R, Perez J, Rink M, Pavan A (1997) Yield criteria for amorphous glassy polymers. J Mater Sci 32(5):1371-1379

198. Ognedal AS, Clausen AH, Polanco-Loria M, Benallal A, Raka B, Hopperstad OS (2012) Experimental and numerical study on the behaviour of PVC and HDPE in biaxial tension. Mech Mater $54: 18-31$ 